\title{
Recognition of Transgender Community in Domestic Legal Regime: A Comparative Analysis between Sri Lanka and India
}

\author{
Aruni Hemanthi Wijayath \\ Independent Researcher, Sri Lanka
}

\begin{abstract}
Transgender is an Umbrella term to define the people whose gender identity and gender expression differ from their gender assign at birth. At present, the concept of transgender has acquired a great attention in the western world and the number of territories legally validate the transgender community and their rights through national legislations. Concerning South Asian context, the third gender concept is recognized by the Indian Supreme Court but unfortunately, the legal system of Sri Lanka is reluctant to amend the laws to ameliorate the position of the transgender community. This research mainly focused on transgender identity and the laws relating to the transgender community in Sri Lanka and India. The purpose of the research is to examine the existing laws relating to transgender identity in both countries. Moreover, this piece of work tries to identify the contribution of law in improving the position of the transgender community in these territories. Further, this work mainly used the comparative research method and based on internet retrieved documents. Through this work it suggests and identifies the ways and means to improve the condition of Sri Lankan transgender community. Recommendations will be made in this respect.
\end{abstract}

Keywords: transgender community, third gender, legal system, legal recognition, society

\section{Introduction}

The sex of a human being depends on biological factors of personality. The gender of a person depends on various factors such as social and cultural factors other than the biological factors. The gender is described as being a male or female otherwise masculine or feminine. South Asian culture identifies only two genders as male and female. The concept of "Third Gender" is acquired a great attentiveness in the general public even though the legal recognition of the third gender is still problematic in some parts of the South Asian region. From ancient history, the concept of the third gender has widely existed in the Asian region. The popular religions in the South Asian region such as Hinduism and Buddhism discuss alternative gender apart from male and female. Ancient Indian literature such as "Kama Sutra" mentions a specific gender apart from main genders of female and male.

In the year 2007 Nepal has recognized the third gender community and protect their rights by their constitutional provisions and in 2013 Bangladesh government also recognized Hijras as a separate gender group apart male and female. Further, through a decision made by the Supreme Court of India in the year 2014, recognized the third gender community as a separate gender in India. But Legal System of Sri Lanka does not identify the third gender concept, although a limited recognition has offered them through administrative decisions made by certain institutions such as the Ministry of Health and Department of Registrar General.

The parliament of the United Kingdom has introduced the Gender Recognition Act in the year 2004. This act vests power to the people who are having gender dysphoria to change their gender according to their preference. Further, the Gender Identity Law in Argentina has acquired great attention in the globe as it offers the freedom to the citizens of Argentina to choose their gender identity with their consent as a legal right. Unfortunately, Sri Lanka is in the backwater of contemporary developments of third gender recognition, at the same time neighbouring countries such as India and Nepal have taken several steps forward to legally recognize the third gender. 
Through this work, the researcher attempts to identify the existing laws and governmental regulations and comparatively analysis them with regard to third gender recognition in both Sri Lankan and Indian context. The global contemporary developments regarding third gender concept may be explored through this paper. This research analyses the possibilities of adopting appropriate existing laws from the Indian legal system to Sri Lanka with constructive changes to legalize the third gender concept in Sri Lanka.

\section{Literature Review}

There is a dearth in researches with relation to Transgender Community in Sri Lanka. Even though a large number of researches could be found in the Indian context and a considerable number of reports issued by national and international organizations could be retrieved easily.

In their work Chandrathilake et al (2015) mentioned that "Sri Lanka is in the backwater of the global gay right village requires no further explanation". Asia or South Asia has no strong mechanism or recognized institution like the European Union in relation to gay rights".

Kharti (2017) through her study mentioned that "the treatment of Indian's hijra community sounds familiar and that is largely because it is reminiscent of the treatment of untouchable in India over a years as a result of caste system". Further, she stated that "conversely recent years have marked a moment of changes in the plight of India's transgender community. With a radical decision in 2014, the Supreme Court of India legally recognized the third gender and mandated inclusive treatment for those identifying in such gender in all castes."

In her work Pullet mentioned that "in Sri Lanka, there seems to be an absence or lack of knowledge of structured communities of transgender people like the trans-communities in the rest of South Asia and parts of South-East Asia. The absence of or lack of knowledge of a community of transgender people in Sri Lanka, like the Hijra community in India makes the concept of the third gender as third sex somewhat alien to them. In India, there have been various efforts to incorporate the third gender into the mainstream. The community has been involved in many fights to get their identity recognized officially."

The United Nations Development Programme report on Hijras/Transgender Women in India: HIV, Human Rights and Social Exclusion, issued in 2010 express that "in India, people with a wide range of transgenderrelated identities, cultures, or experiences exist - including Hijras, Aravanis, Kothis, Jogtas/Jogappas, and ShivShaktis. Often these people have been part of the broader culture and treated with great respect, at least in the past, although some are still accorded particular respect even in the present".

\section{Research Statement}

The existing laws and administrative decisions of Sri Lanka, reluctant to offer adequate support to recognize non-binary or third gender community, comparatively with the Indian legal system.

\section{Objectives}

1. To identify existing fundamental rights and other administrative decisions concerning the third gender in Sri Lanka

2. Compare the existing laws and regulations in Sri Lanka and India in relation to non-binary gender recognition

3. To propose the possible recommendation to recognize the third gender community in Sri Lanka and support to ameliorate their dignity through the outcome of this work 


\section{Methodology}

The normative method is used to complete this research and based on the documentary analysis qualitatively. Through this work internet-based scholarly articles, paper articles, judgments, acts and regulations may be explored. The statutory provisions, judicial decisions, governmental regulations relevant to this topic may be strongly analyzed as the primary source. As the secondary source, the internet-based scholarly articles, paper articles, web site articles and reports may be retrieved.

\section{Limitations}

Even though this research based on the third gender community, it did not critically evaluate the Indian court decisions regarding the recognition of the transgender community. Further none of the legislations except the Constitutions of India and Sri Lanka were critically examined to identify the legal recognition of the Transgender community in both countries. Especially the Penal Laws and other by-laws were not explored through this research in order to understand the actual position of the transgender community in the legal arena of both territories. Further, a few numbers of researches were explored to understand the third gender community in Sri Lanka due to the dearth of research in relation to this area in the Sri Lankan research database. The work analyzed only internet-based documents.

\section{Discussion}

Under this part, three main topics will be discussed. The first part, the history of third gender concept in Sri Lanka and India will be observed and in the middle part, the third gender recognition in Sri Lankan context will be analyzed. In the latter part, the position of the third gender community in Indian legal system will be retrieved.

\section{History of Third Gender Identity in India and Sri Lanka}

Both India and Sri Lanka have acquired a great attentiveness around the globe due to the archaic histories of the two countries and from the ancient times, these two territories are correlated with each other by the religions, culture, geographical factors and diplomatic relations. India has a widespread cultural and religious diversity whereas Sri Lanka also experienced multi-cultural relations. But the Indian concept of the third gender spreads to a vast area and ancient history bear-out on existence a gender apart from the main two genders.

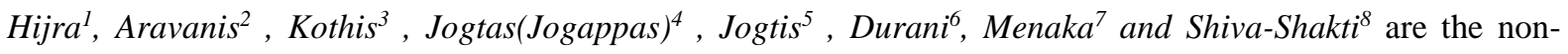
binary genders which could be found in India.

\footnotetext{
${ }^{1}$ Habitat mainly In India, Nepal and Bangladesh and could be identified as a social group or a caste. They are identified as "neither men nor women". They are biological males but rejected their masculine identity and behave like women. They are having a historical tradition and they believe that they are the power of Goddess" Buhuchara Mata"

2 Also called as "Thirunangi".Hijra people who are habitat in Tamil Nadu identify as "Aravani"

${ }^{3}$ Heterogeneous group. Man or boy who effeminate (often more associated with feminine behaviours) and take part in the female gender role in a same-sex relationship. Differ from Hijra community as Korhis do not live as a community. Some people are bisexual and some are getting married to a woman.
} 
Kama Sutra the ancient Sanskrit literature written by Vathsalyana in between 400 BCE -200 BC mentioned about the sexual lives of people with "Third Nature (Tritiya Prakriti)" ${ }^{\prime}$. The Vedas ${ }^{10}$ (1500Bc-500 BC) described the individuals who are belonging to third nature. ${ }^{11}$ The pioneering work on Hindu law "Manu Smiriti" 12 and ancient literature "Mahabharathya ${ }^{13}$ " gave evidence of the existence of a third gender. ${ }^{14}$ In the Mughal period ${ }^{15}$ of India, Hijra community played a wide role in Indian monarchy and they acquired a great dignity. They were very trustworthy servants to Mughal Kings and acted as main administrative role in King's palace in the Mughal era such as political advisors and administrators. ${ }^{16}$

In the Sri Lankan context, the existence of the third gender or transgender is not clearly defined in historical sources. But the main religion of Sri Lanka, Buddhism has given documentary evidence in the existence of the third gender. In the "Vinaya Pitaka"17 codified in 2 BC contained the Lord Buddha's sermons to the Buddhist monastic community which comprehend their disciplinary code. Through these discourses, it is revealed that the

${ }^{4}$ Male servants who are dedicated and serve to goddess Yellamma (Renuka Devi) from their family tradition. Some Jogtas wear female attire when worship goddess Yelamma but some are not.

${ }^{5}$ Female servants who are dedicated and serve to Goddess Yellamma. They are called "devadasi" also.

${ }^{6}$ Kothi people who habitat in Calcutta

${ }^{7}$ Kothi people who habitat in Cochin

${ }^{8}$ Male people who are more close to the goddess and who are having feminine gender expression. Occasionally they are crossdressers.

${ }^{9}$ Michelraj, M., Historical Evaluation of Transgender Community in India,2015, Asian Review of Social Sciences, Vol 4, No 1,pp17-19

${ }^{10}$ Collection of hymns and other ancient religious texts written in India. Parts of Vades were composed in different eras and there are 4 main vades

${ }^{11}$ Michelraj, M., Historical Evaluation of Transgender Community in India,2015, Asian Review of Social Sciences, Vol 4, No 1,pp17-19

12 Manu-Smriti, (Code of Manu, "Laws of Manu" or "The Remembered Tradition of Manu").The 1st book written in the world regarding the law and it contains the social and moral conduct of a person.

${ }^{13}$ One of the major two Sanskrit epics in India and the other one is Ramayanaya.

${ }^{14}$ Michelraj, M., Historical Evaluation of Transgender Community in India,2015, Asian Review of Social Sciences, Vol 4, No 1,pp17-19

${ }^{15}$, Hindu- Islamic kingdom situated in Northen part of India and this era Turkic-Mongol origin dynasty kings were ruled from 1556 to 1707

${ }^{16}$ Michelraj, M., Historical Evaluation of Transgender Community in India,2015, Asian Review of Social Sciences, Vol 4, No 1,pp17-19

${ }^{17}$ The regulatory and discipline code for the monastic community of Buddhism 
Lord Buddha sermonized that the existence of another two genders apart from male and female ${ }^{18}$. They are "ubhatobyañjanaka" 19 (people of a dual sexual nature) and "pandaka" ${ }^{20}$. With the new developments to the Vinaya Pitaka the "Pandaka" term used to denote the third gender community who are having male or female bodies but the inconsistency with the natural characteristic of woman or $\operatorname{man}^{21}$.

At present, the third gender or transgender community in Sri Lanka is not much popular as India. Their culture is not complicated as Indian culture and they are named as "Nachchi, Napunsaka (eunuch), Pandakaya (derived from Vinaya Pitaka term) or Ponnya (disguising Sinhala term). All these terms are used to describe trans women although trans males do not have a unique identity in Sri Lanka. Therefore in generally the umbrella term "transgender" or term "sexual minorities" is used to introduce the LGBTIQ ${ }^{22}$ the community in Sri Lanka and they do not have a unique identity as Indian third gender community.

\section{Recognition of Third Gender Community in Sri Lanka}

The Constitution of Sri Lanka does not explicitly recognize the gender as a ground of discrimination or as a ground of disability to enjoy the equal opportunity although the sex is identified as a ground of discrimination.

Article 12 (2) of the Constitution states as follows;

"No citizen shall be discriminated against on the grounds of race, religion, language, caste, sex, political opinion, place of birth or any one of such grounds",

Under Article 12 (3)

"No person shall, on the grounds of race, religion, language, caste, sex or any one of such grounds, be subject to any disability, liability, restriction or condition with regard to access to shops, public restaurants, hotels, places of public entertainment and places of public worship of his religion"

These two articles revealed that the Constitution does not identify gender as a ground of discrimination. Even though the rule "eusdem genaris (of the same kind)" 23 " could be used to interpret the term "any one of such ground" contained in article 12 (2) and 12 (3). Through the light of this rule, the "gender" could be proposed to categorize as a type of discrimination ground. Under Article $125(1)^{24}$ of the constitution pronounces that the Supreme Court of Sri Lanka has the sole and exclusive jurisdiction to hear and determine any question relating

18 Jackson, Peter A. (April 1996). "Non-normative Sex/Gender Categories in the Theravada Buddhist Scriptures". Australian Humanities Review

${ }^{19}$ People who are having both male and female sex nature

${ }^{20}$ People who are having deficiencies in their male sex nature

${ }^{21}$ Gyatso, J. (2003). "One Plus One Makes Three: Buddhist Gender, Monasticism, and the Law of the Non-Excluded Middle". History of Religions. 43 (2): 89-115

${ }^{22}$ LGBTIQ defines L-Lesbian, G-Gay, B-Bisexual, T-Transgender, I-Intersex-Queer or questioning people

${ }^{23}$ General words follow specific words in a statutory enumeration, the general words are construed to embrace only objects similar in nature to those objects enumerated by the preceding specific words."

${ }^{24}$ Article 125 (1)- The Supreme Court shall have sole and exclusive jurisdiction to hear and determine any question relating to the interpretation of the Constitution 
to the interpretation of the Constitution. Therefore the interpretation of aforementioned articles and phrases would be accomplished by the Supreme Court of Sri Lanka but unfortunately, none of the case has reached the Supreme Court to hear and determine the rights of third gender community in relations to these articles.

None of the provisions of the existing constitution of Sri Lanka which explicitly recognize the existence of the third gender in Sri Lankan context. At present, the Government of Sri Lanka is struggling to introduce a new Constitution which addresses the contemporary developments of the country. To achieve this target a panel of experts through the Constitutional Reform Committee introduced and recommended new reforms to the constitution. Through these recommendations, they proposed to annex "gender, gender identities and gender orientations" as another ground of discrimination to be amended to the new constitution ${ }^{25}$. Further, the committee proposed to amend the constitution with a separate new chapter which discusses and protects the rights of diverse sexual and gender identities. ${ }^{26}$ Unfortunately, these recommendations also becoming another pending amendment to the constitution and none of the authorized institutions steps forward to take necessary actions to enforce these recommendations through legislator. For these reasons, the third gender community has not yet received legal recognition in Sri Lanka.

Before the year 2016, obtaining an amended birth certificate is a desperate or unrealizable task in Sri Lanka. But in the year 2016, a new regulation has introduced by the Ministry of Health collaborated with the Registrar General Department to amend the birth certificate of transgender persons. Through this procedure, the person who sought to changes his/her gender in his identification documents should obtain a Gender Recognition Certificate. To obtain a Gender Recognition Certificate an evaluation of a psychiatrist, hormone therapy and necessary surgical operations should be accomplished by the transgender person. In other words, this certificate can only be obtained by the persons who undergo the medical procedure and no one can obtain the certificate without following the medical treatments and surgical operations. Practically, undergo this medical treatment is a difficult and cost-effective task in Sri Lanka.

This procedure has evolved by an administrative decision made by the authoritative persons of relevant governmental institutions and does not have any legislative power which vested by an act passed by the Parliament of Sri Lanka. Further, any person who follows these administrative decisions could change their gender from male to female or female to male-only. No one can introduce him/her as a "third gender or other" person apart from male or female. Therefore it reveals that the "third gender" concept cannot be practically applied in official documents in Sri Lanka as the third gender concept is not yet recognized by the legislation and by-laws of Sri Lanka.

\section{Third Gender concept in India}

In India the concept of transgender is almost all differ from Sri Lankan context. Before the year 2014, legal gender recognition of the transgender community in India was in the same position as in Sri Lanka. Under article 14 of the constitution of India states that

"The State shall not deny to any person equality before the law or the equal protection of the laws within the territory of India"

Further Article 15(1) states that:

25 Public Representations Committee on Constitutional Reforms, May 2016 https://www.yourconstitution.lk/FPRCRpt/FPRC_english_report-A4\&gs_[last visited 4th June 2018]

${ }^{26}$ ibid 
"The State shall not discriminate against any citizen on grounds only of religion, race, caste, sex, and place of birth or any of them."

Article 15 (2):

"No citizen shall, on grounds only of religion, race, caste, sex, place of birth or any of them, be subject to any disability, liability, restriction or condition with regard to-

(a) Access to shops, public restaurants, hotels and places of public entertainment; or

(b) The use of wells, tanks, bathing ghats, roads and places of public resort maintained wholly or partly out of State funds or dedicated to the use of the general public."

Article 16 of the Constitution emphasizes

16. (1) There shall be equality of opportunity for all citizens in matters relating to employment or appointment to any office under the State.

(2) No citizen shall, on grounds only of religion, race, caste, sex, descent, place of birth, residence or any of them, be ineligible for, or discriminated against in respect of, any employment or office under the State.

These provisions do not recognize gender as a ground of discrimination in India. But in the year 2014, the Supreme Court of India through a landmark judgment changed the attitude and reception of law regarding legal gender recognition concept. National Legal Service Authority v. Union of India, AIR 2014 SC 1863, the landmark case that ameliorates the position of Indian transgender community. Through this Judgment, the court recognized the transgender communities such as Hijras, Aravanis, Jogappas, and Shiva Shakti etc as the "third gender" in India. Further, the court held that the "gender identity is an integral part of the personality and one of the most basic aspects of self-determination, dignity and freedom. Thus, no one can be forced to undergo medical procedures, including sex reassignment surgeries, sterilization or hormonal therapy as a requirement for legal recognition of their gender identity." Further, it emphasized that choosing own gender identity falls within the scope of the right to life. ${ }^{27}$

Moreover, the court acknowledged that the term "citizen and person" could equally apply not only to men and women but also to transgender persons also. Under article 15 and 16 of the Constitution, the "gender" has not identified as a ground of discrimination. But through the judgment National Legal Service Authority v. Union of India, it emphasized that the term "sex" is to be understood as all forms of discrimination under gender and gender-based violence.

The court declared that every human has the right to self-determine about their gender identity and everyone has an equal right, equal opportunity and protection despite their sexual orientation and gender identity. As well, the court upholds that the third gender community has the right to freedom to express their identity through attire, words, actions and behaviours.

"Yogyakarta principles"28 a set of rules that address gender identity and sexual diversity. The sovereign states are not binding by these principles even though the Indian Supreme Court adopted these principles to address

\footnotetext{
27 Under Article 21 of the Constitution of India "Right to life" is categorized under
} fundamental rights of its citizens.

${ }^{28} \mathrm{~A}$ set of principles of application of international human rights law in relation to sexual orientation and gender identity. This document addresses 29 principles that are important to LGBTIQ people. In the year 2017, another set of additional principles were amalgamated to the Yogyakarta principles and they are called "Yogyakarta Principles plus 10 
the issues of the transgender community. Universal enjoyment of human rights, right to equality and nondiscrimination, right to recognition before the law are few cardinal rights mentioned by the Supreme court of India which enunciated by Yogyakarta principles. The third principle of Yogyakarta document ${ }^{29}$ mentioned that "no one shall be forced to undergo medical procedure including sex re-assignment test, sterilization, or hormonal therapy as a requirement for legal gender recognition."

The position of Indian transgender community is in advance stage while comparing with other Asian countries. The transgender community in India fought for their rights for legal gender recognition. From these efforts, they acquired a number of rights and opportunities. For example, in the year 2009, the election commission of India permitted the transgender community to put "O" denoted by "other" as their gender when indicating their sex in Voter Identity Form. In some states of India such as Kerala and Tamil Nadu perform gender reassignment surgeries for free in selected government hospitals ${ }^{30}$. Railway reservation and cancellation forms, passports, bank forms and Ration cards of India contained the option of the third gender besides male and female. ${ }^{31}$ Before the landmark judgment of Supreme Court regarding transgender community, in the year 2013, the resolution has passed by Department of Food and Civil Supplies of Gujarat state, offered the opportunity to transgender people to indicate their gender as "other" in their Ration Cards. This information reveals that the flexibility of state authorities of India upholds the position and legally recognize the transgender community.

In Tamil Nadu state, a landmark initiative "Tamil Nadu Aravanigal (Transgender) Welfare Board" was established in the year 2008 to address the issues of transgender community habitat in Tamil Nadu. For the first time, the board conducted a census for third gender community in Tamil Nadu ${ }^{32}$.The welfare board collaborated with the Food and Civil Supplies Department, issue a Ration Card for the maintenance of low-economical third gender community ${ }^{33}$. Further, some states including Tamil Nadu issue Identity Cards to the transgender community stating their gender as "Aravani". ${ }^{34}$ The Kerala state has taken a step to support the right to education of the transgender community by opening the first transgender school in 2016 at Thrikkakara in Kerala's Ernakulam district. ${ }^{35}$

All these facts reveal that the recognition of the third gender concept is widely accepted by both the Indian court and other governmental institutions.

\section{Discussion}

Last two topics separately discuss the current situation of legal gender recognition in both Sri Lanka and India. India has a multi-cultural society comprised of various religious, ethnic groups and caste system other than Sri Lanka. Both Indian and Sri Lankan criminal legal systems derived from the same root of English Criminal Law.

\footnotetext{
${ }^{29}$ Principle 3-Right to recognition before the Law

$30 \mathrm{https} / / /$ scroll.in/article/804496/why-keralas-free-sex-change-surgeries-will-offer-a-newlifeline-for-the-transgender-community

${ }^{31}$ https://thewire.in/gender/third-gender-railway-forms-passport-voter-id

32 HIJRAS/TRANSGENDER WOMEN IN INDIA: HIV, HUMAN RIGHTS AND SOCIAL EXCLUSION, 2010, United Nations Development Project

${ }^{33}$ Ibid

${ }^{34} \mathrm{Ibid}$

35 https://indianexpress.com/article/education/indias-first-transgender-school-opens-inkerala-4452162/
} 
The Penal Code of Sri Lanka could be treated as the carbon copy of Indian Penal Code as both codifications having plenty of similarities. Further, the Sri Lankan Justice System frequently adopts appropriate contemporary developments in relation to judgments and legislation from the Indian Justice System. But unfortunately the criminal justice system of Sri Lanka inattentiveness and reluctant to adopt the contemporary developments in relation to the third gender concept of India.

With regard to India, the court cases related to transgender or third gender disputes are few and far between reached to the courts in Sri Lanka. Therefore the judiciary in Sri Lanka rarely gets an opportunity to interpret or adapt the relation of the contemporary development to transgender laws in the concurrent world. But in the Indian context, the transgender community is one of the dominant categories and their voice is stronger than Sri Lanka's transgender community to demand their social security and legal recognition. Therefore the Indian judges are getting plenty of opportunities to open new dimensions through legal interpretations in relation to the laws and rights of the transgender community.

According to the World Health Organization, the healthcare system of Sri Lanka far better than the healthcare system of India. But unfortunately, Government hospitals of Sri Lanka do not have any proper mechanism or programme to perform gender reassignment surgeries and hormonal therapy which targeting the transgender community. The health care workers and other hospital staff treat the transgender community as mentally ill persons or mentally deviant individuals ${ }^{36}$. Further, a considerable percentage of transgender persons are sex workers in Sri Lanka ${ }^{37}$, therefore, a proper mechanism should be there to screening them for Sexually Transmitted Diseases (STD) and HIV. The government STD clinics are performing screening tests for the general public but unfortunately, there are no special clinics for the transgender community to screening them for STDs and other diseases. But in India, the health system pays more attention to the transgender community and facilitate them.

By issuing Gender Recognition Certificates Sri Lanka put a step forward to recognize the third gender community. But unfortunately, the certificate obtaining procedure is an impassable way comprised of several obstacles. Without necessary hormonal therapy, surgeries and psychiatrist's evaluation report, the certificate obtaining procedure becoming inability. Therefore obtaining amended birth certificates and other identification documents which revealed the present gender of transgender people becoming a fruitless effort. But the Supreme Court of India emphasized that the gender identity of persons is based on self-determination and anyone cannot force to undergo any hormonal therapy or any other medical procedures to change their gender without their consent. But unfortunately, Sri Lanka indirectly forcing the people to follow medical procedures through the administrative circulars who need to change their gender. Without undergoing these medical treatments anyone cannot change their gender in the Sri Lankan context.

In Sri Lanka, the legislative power of the people is exercised by the parliament ${ }^{38}$ and the parliament has the power to enact laws and amend the Constitution. ${ }^{39}$. Its legislative power cannot be abdicated or alienated in any

\footnotetext{
36 Country Policy and Information Note Sri Lanka: Sexual orientation and gender identity,2017, United Kingdom Home Office Report https://www.gov.uk/government/publications/sri-lanka-country-policy-and-informationnotes

${ }^{37}$ ibid

${ }^{38}$ Article 4 (a) of the Constitution

${ }^{39}$ Article 75 of the Constitution.
} 
circumstances ${ }^{40}$ by the parliament. The other circulars and regulations promulgated by administrative authorities have less binding power while compared with the acts passed by the parliament.

The circular regarding Gender Recognition Certificate has issued by the Director-General of Health under circular No 01-34/2016 and the Registrar General Department issued the circular No 6/2016, that empowers the authority to District Registrars and other authoritative persons to amend the birth certificates in accordance with Gender Recognition Certificate. Hence issuing Gender Recognition Certificates is only an authoritative decision made by the executive body based on the discretion of particular administrative authorities and cannot execute as a legal right under the laws of Sri Lanka as this process does not incorporate or assimilate to the domestic legal regime through legislations.

Argentinean Gender Recognition Law could be treated as landmark legislation in relation to transgender identity in the globe. Under this law, every person has the right to recognize their gender identity. Article 2 of the act states that "the gender identity is understood as an internal and individual way in which perceived by the person $^{41}$ ". The Argentinian who are requesting to change their gender, need not prove that they undergo any medical, hormonal or any other treatments. ${ }^{42}$

While carefully studying these instrumental factors, it is revealed that the existing laws and administrative decisions made by Sri Lanka reluctant to offer adequate support to recognize non-binary or third gender community comparatively with the Indian legal system. Therefore Sri Lanka should take immediate necessary actions to introduce a mechanism to recognize the third gender community and ameliorate their position in Sri Lankan context.

\section{Recommendations}

Sri Lanka should amend the Constitution and adopt comparative developments regarding third gender concept and expressly declare the gender should not be a ground of discrimination while enjoying fundamental rights. While consolidating the new Constitution, the recommendations of the Constitutional Reforms Committee regarding sexual orientation and gender diversity such as the proposed separate chapter for sexual minorities' rights could be implemented and practised through the forthcoming constitution.

New laws should be introduced to recognize the gender identity of transgender persons and a separate act should be introduced which addresses the current issues such as education, housing, healthcare and equal employment opportunities to the transgender community. In all the documents and forms issued by private and government sectors should indicate the "other" apart male and female in the category of gender.

${ }^{40}$ Parliament shall not abdicate or in any manner alienate its legislative power and shall not set up any authority with any legislative power

41 Article 2-Gender identity is understood as the internal and individual way in which gender is perceived by persons, that can correspond or not to the gender assigned at birth, including the personal experience of the body. This can involve modifying bodily appearance or functions through pharmacological, surgical or other means, provided it is freely chosen. It also includes other expressions of gender such as dress, ways of speaking and gesture (English Translation of Argentina's Gender Identity Law as approved by the Senate of Argentina on May 8, 2012)

42 Article 4- In no case will it be needed to prove that a surgical procedure for total or partial genital reassignment, hormonal therapies or any other psychological or medical treatment has taken place. 
The Health Ministry needs to take necessary actions to issue Gender Recognition Certificates through a simple procedure without forcing to undergo any medical or surgical procedures to change the sex of the person's. A proper mechanism which could be easily put into practice, need to introduce to issue Gender Recognition Certificates and to amend identification documents instead of a current laborious procedure.

The judiciary takes into account to actively participate to interpret the laws creatively and the humanitarian manner in relation to the transgender community to bring equal protection and proper recognition mechanism for them. Further, the Judges urge to concern on the contemporary developments around the globe and endeavour to adapt them to the justice system of Sri Lanka through their judgments as they are the pioneers of interpreting the laws.

The transgender activists of Sri Lanka need to be more attentive and their voices should be more sharpen to represent on behalf of sexual minorities. They should put their steps forward to bring the issues to the courts and seek legal recognition for the sexual minorities. Furthermore filing Fundamental Rights cases on behalf of sexual minorities in the Supreme Court under Public Interest Litigation may be fruitful assay to enhance the dignity of sexual minorities in Sri Lanka context. Finally, the academics, Human Rights activists and social activists should impel the government to take necessary actions to legalize the third gender concept in Sri Lanka.

\section{References}

Carol S. Anderson, 2016, Changing Sex in Pāli Buddhist Monastic Literature, https://www.researchgate.net/profile/Carol_Anderson/publication/313629904_Changing_Sex in_Pali_Buddhist _Monastic_Literature/links/58a082dbaca272046aad5d16/Changing-Sex-in-Pali-Buddhist-Monasticliterature.pdf?origin=publication detail accessed 21st June 2018

Chandrathilake, MAN., Mahanamahewa, P,2015, Sexual Orientation and Human Rights: Applicable Laws of Sri Lanka and the UK, Proceedings of 8th International Research Conference, KDU, Published November 2015 [pdf], >https://scholar.google.com/citations?user=MVB8-0QAAAAJ\&hl=e>accessed on 23rd June 2018

Constitution of india.pdf https://www.india.gov.in/sites/upload_files/npi/files/coi_part_full.pdf accessed 23rd June 2018

Country Policy and Information Note Sri Lanka: Sexual orientation and gender identity, 2017, United Kingdom Home Office Report https://www.gov.uk/government/publications/sri-lanka-country-policy-and-informationnotes accessed 16th June 2018

Devina Das, The Transgender Citizenry in India: Actors on a Flimsy Ground and the Legal Lacunae, International Journal of Law and Legal Jurisprudence Studies: Volume 3 Issue 1, http://ijlljs.in/wpcontent/uploads/2016/02/29.pdf accessed 16th June 2018

Dona John, Living a Life of Exclusion: Being a Transgender in India, 2017, pdf <http://fnst.org/sites/default/files/uploads/2017/11/20/focuahumanrights-rightsoftransgenderi> accessed 19th June 2018

Dr P.G Maheepala, Director General of Health, Issuing of Gender Recognition Certificate for Transgender Community, General Circular Number-01-34/2016,16 June $2016<$ http://hrcsl.lk/english/wpcontent/uploads/2016/08/GRC-E.pdf> accessed on 23rd June 2018

English Translation of Argentina's Gender Identity Law as approved by the Senate of Argentina on May 8, 2012, < https://tgeu.org/argentina-gender-identity-law/> accessed on 24th June 2018

Human Right Watch, 2016, All five fingers are not same, Discrimination on Grounds of Gender Identity and Sexual Orientation in Sri Lanka, [pdf] https://www.hrw.org/sites/default/files/report_pdf/srilanka0816web.pdf accessed 25th June 2018].

Human Rights Commission of Sri Lanka Proposals for Constitutional Reform - 2016 [pdf] hrcsl.lk/english/.../2016/.../Proposals-for-Constitutional-Reform-by-HRC-in-English...accessed 24th June 2018 
International Gay and Lesbian Human Rights Commission, 2014, Violence Against Lesbians, Bisexual Women and Transgender Persons in Sri Lanka (Presented to the 112th Session of The Human Rights Committee of the United Nations International Covenant on Civil and Political Rights), <http://www.refworld.org/pdfid/58c2b6444.pdf> accessed 19th June 2018

Joint Submission for 3rd cycle UPR review of Sri Lanka, Coalition of NGO's for UPR-Sri Lanka (SOGI), Human Rights violations against LGBTIQ individuals in Sri Lanka [pdf] https://www.ilga.org/downloads/stakeholders_report_SriLanka_UPR28.pdf

M. Michelraj, 2015, Historical Evolution of Transgender Community in India, Asian Review of Social Sciences Vol. 4 No. 1, 2015, pp. 17-19 < http://www.trp.org.in/wp-content/uploads/2015/10/ARSS-Vol.4-No.1-JanJune-2015-pp.17> accessed 21st June 2018

National Legal Services Authority V Union of India and Others [2014] (Writ Petition No. 400 of 2012 with Writ $\begin{array}{lllll}\text { Petition } & \text { No. } & 604 & \text { of } & 2013)\end{array}$ http://orinam.net/377/wpcontent/uploads/2014/04/Judgement_Nalsa_Transgenderrights.pdf > accessed 23rd June 2018

Neena Sawant, Transgender Status in India,2017, pdf <https://www.researchgate.net/profile/NeenaSawant/publication/322012741_Transgender > accessed 17th June 2018

Sapna Khatri, 2017, Hijras: The 21st Century Untouchables, Washington University Global Studies Law $\begin{array}{llllll}\text { Review } & \text { Volume } & 16 & \text { Issue } & 2, & <\end{array}$ https://openscholarship.wustl.edu/cgi/viewcontent.cgi?article=1619\&context=law_globals $>$ accessed 21st June 2018

Sourav Agarwal, 2017, Civil and Political Rights of Transgenders In Indian Constitutional perspective, International Journal of law and legal jurisprudence studies: Volume 4 Issue 4, Special Issue < http://ijlljs.in/wpcontent/uploads/2017/12/ARTICLE_ON_TG_1-1.pdf > accessed 18th June 2018

The Constitution of the Socialist Republic of Sri Lanka

United Nations Development Programme India, Hijras/Transgender Women in India: HIV, Human Rights and

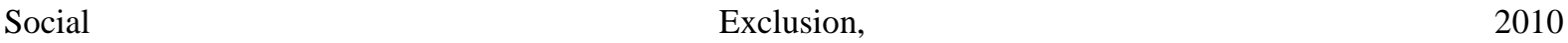
<http://www.undp.org/content/dam/india/docs/hijras_transgender_in_india_hiv_human_rights_and_social_excl usion.pdf $>$ accessed 18th June 2018

Urmila Pullat, "Transgendered in Sri Lanka: Gender Identity and the Law in Sri Lanka and India"< http://ssrn.com/abstract=2425503> accessed 18th June 2018

Venkatesan Chakrapani, 2012, The Case of TAMIL NADU TRANSGENDER WELFARE BOARD: Insights for Developing Practical Models of Social Protection Programmes for Transgender People in India. United Nations Development Project, < $\underline{\text { http://www.undp.org/content/dam/india/docs/HIV and development/the-case- }}$ of-tamil-nadu-t $>$ accessed 24th June 2018

Equal Ground Sri Lanka, 2017, Violations by Sri Lanka of Economic, Social and Cultural Rights of Lesbian, Gay, Bisexual, Transgender, Intersex and Questioning People, 61st session of the Committee of Economic, Social and Cultural Rights, May 2017,[pdf] <https://www.INT_CESCR_CSS_LKA_27401_E.pdf> accessed 20th June 2018 